\title{
Fundamental Volatility is Regime Specific
}

\author{
Ivo J.M. Arnold* \\ Universiteit Nyenrode, Breukelen, The Netherlands \\ Ronald MacDonald \\ University of Glasgow, Glasgow, United Kingdom \\ Casper G. de Vries \\ Erasmus University Rotterdam and Tinbergen Institute \\ Rotterdam, The Netherlands
}

November 2005

\begin{abstract}
A widely held notion holds that freely floating exchange rates are excessively volatile when judged against fundamentals and when moving from fixed to floating exchange rates. We re-examine the data and conclude that the disparity between the fundamentals and exchange rate volatility is more apparent than real, especially when the Deutsche Mark, rather than the dollar is chosen as the numeraire currency. We also argue, and indeed demonstrate, that in cross-regime comparisons one has to account for certain 'missing variables' which compensate for the fundamental variables’ volatility under fixed rates.
\end{abstract}

Keywords: Exchange rates; Exchange rate regimes; Excess volatility.

JEL classification: F31

\footnotetext{
* Contact details: Ivo J.M. Arnold, Universiteit Nyenrode, Straatweg 25, 3621 BG Breukelen, Netherlands (email: i.arnold@nyenrode.nl); Ronald MacDonald, Department of Economics, University of Glasgow, Adam Smith Building, Room S102, Glasgow G12 8RT, Scotland (email: r.macdonald@socsci.gla.ac.uk); Casper G. de Vries, Erasmus University Rotterdam, Tinbergen Institute, H14-25, PO Box 1738, 3000 DR Rotterdam, Netherlands (email: cdevries@few.eur.nl).
} 


\section{Introduction}

The early proponents of flexible exchange rates (see, for example, Friedman, 1953, Sohmen, 1961 and Johnson, 1958) viewed the fixed but adjustable Bretton Woods exchange rate arrangement as inherently unstable, because it failed to provide an effective adjustment mechanism. In contrast, a regime of flexible exchange rates was regarded as providing an automatic adjustment mechanism and flexible rates were therefore predicted to be inherently stable. However, the post-Bretton Woods and inter-war experiences with flexible exchange rates suggest that exchange rates when left to their own devices are inherently volatile. Of course, this does not mean that such rates are excessively volatile, since as Friedman recognized, if the underlying fundamentals are unstable then exchange rates are likely to be unstable as well:

Instability of exchange rates is a symptom of instability in the underlying economic structure. Elimination of this symptom by administrative freezing of exchange rates cures none of the underlying difficulties and only makes adjustment to them more painful. (Friedman, 1953)

However, the so-called exchange rate disconnect discussed in Obstfeld and Rogoff (2000) summarizes a widely held belief in the profession that exchange rates have indeed been excessively volatile with respect to traditional macroeconomic variables in the post-Bretton Woods period. ${ }^{1}$ There are two aspects to this volatility disconnect in the literature, and we label these inter- and intra-regime volatility. Inter-regime volatility refers to the striking result that in moving from a system of fixed to floating exchange rates, the volatility of macroeconomic fundamentals, such as the money stock and income, does not change, but the volatility of the exchange rate does. The concept of intra-regime volatility refers to the view that in floating exchange rate regimes exchange rates appear to be excessively volatile with respect to the fundamentals.

The issue of inter-regime volatility has been made in a number of papers. For example, Baxter and Stockman (1989) examine the variability of output, trade variables, private and government consumption and the real exchange rate and are "unable to find evidence that the cyclical behavior of real macroeconomic aggregates depends systematically on the exchange rate regime. The only exception is the well-known case of the real exchange rate.” Flood and Rose (1995) use flexible price and sticky price variants of the monetary model to show that the volatility of their so-called 'traditional fundamentals' (money and income) stays roughly unchanged in the move from the Bretton Woods to the post-Bretton Woods regime but that the volatility of virtual fundamentals (the exchange rate minus the interest rate differential) increases dramatically. Flood and Rose (1999) present a similar exercise in which they compare the volatility of fundamentals (including the interest differential) with exchange rate volatility per se for the Bretton Woods and

\footnotetext{
${ }^{1}$ The exchange rate disconnect also refers to the apparent difficulty in forecasting (the level of) exchange rates, although this is not uncontroversial.
} 
the post- Bretton Woods period and again find that the volatility of the exchange rate dominates the volatility of the fundamentals. ${ }^{2}$

The notion of intra-regime volatility has also been investigated. For example, Frankel and Meese (1987) note that in the post-Bretton Woods regime nominal exchange rates are clearly more volatile than a standard set of macroeconomic fundamentals, such as money supplies and output, suggest. However, they are careful to avoid referring to this as excess exchange rate volatility since, for example, modifications to exchange rate models along the lines of introducing heterogeneous expectations, instead of rational expectations, may resolve the puzzle. MacDonald (1999) makes a similar point. Nonetheless, the view that exchange rates are more volatile than macroeconomic fundamentals has become something of a stylised fact in the economics profession.

In this paper we propose to re-evaluate the inter-regime and the intra-regime exchange rate volatility issues in a number of ways, some of which are novel. On the theory side we expand the canonical monetary model of floating exchange rates to account for 'missing variables' in the case of regulated markets. Since, for example, the Bretton Woods regime was characterized by fixed exchange rates combined with trade and capital market distortions, an analysis of this regime has to take account of such distortions.

A key novelty in our study lies in the examination of inter-regime volatility and, in particular, the behavior of an expanded set of fundamentals in the Bretton Woods and post-Bretton Woods periods. For these regimes we shift the conventional question from 'why do we not observe enough exchange rate volatility in fixed rate regimes?' to 'which variables do absorb the fundamental volatility?'. We believe that asking the question in this way is insightful since there may be other fundamentals which exhibit variability in these regimes. If exchange rates are fixed, or managed, then it is variables like the interest differential, international reserves or IMF support which adjust rather than the exchange rate. Furthermore, in these regimes there are often other regulated aspects which should be incorporated into any empirical evaluation of the volatility of exchange rate fundamentals. Perhaps the most notable is the existence of capital controls in fixed rate regimes and, as we show, these can have important implications for appropriately gauging the effects of macro fundamentals. We demonstrate that the volatility in the fundamentals is at least partly absorbed by these missing variables. We find evidence for this result using case study evidence and further cross-country evidence. The apparent disparity across regimes is then partly resolved by the fact that one has to use different sets of fundamentals in computing cross-regime comparisons.

\footnotetext{
${ }^{2}$ Duarte (2003) examines the effects of the exchange rate regime in the context of a dynamic general equilibrium model with nominal goods prices set in the buyer's currency and incomplete asset markets. Her model predicts a sharp increase in the volatility of the real exchange rate when moving from fixed to flexible exchange rates. This pattern is not observed for other variables. Reinhart and Rogoff (2002) argue that at least part of the inter-regime volatility puzzle may be explained by using an inappropriate classification of the exchange rate regime. In particular, they show that in moving from the IMF's classification of an exchange rate regime (as used in the studies of Baxter and Stockman (1989) and Flood and Rose $(1995,1999))$ to one based on the actuality of the regime, there was in fact much more flexibility of exchange rates during Bretton Woods and much more fixity during the post-Bretton Woods period.
} 
One particular problem in assessing the volatility of fundamentals in the Bretton Woods fixed exchange rate regime is the paucity of good quality data on, for example, capital controls. To gain insight into the importance of capital controls in affecting the exchange rate fundamentals relationship, we analyse data from the ERM experience with managed exchange rates. Additionally, we use data from the German and US experiences with monetary unions to show that fundamental volatility is reduced, compared to inter-country comparisons, when the exchange rate is permanently fixed, and this accords with the monetary model of the exchange rate.

We re-examine the issue of intra-regime volatility by re-evaluating the relationship between the volatility of macroeconomic fundamentals and the exchange rate in two flexible exchange rate regimes, namely the inter-war experience and the post-Bretton Woods regime. In contrast to the perceived wisdom, we demonstrate that the volatility of exchange rates and fundamentals are quite tightly aligned in these regimes and there is no evidence of excess volatility.

The outline of the remainder of this paper is as follows. In the next section we present an extension of a representative agent monetary model. This model is designed to motivate the kind of traditional fundamentals used in exchange rate studies. It has, however, the further purpose that it clearly shows how volatility of fundamentals may show up in what we call the wedge rather than in the exchange rate, as is usually assumed. In section 3 we empirically investigate the interregime volatility. Subsequently, in section 4 , we study intra-regime under different exchange rate regimes including pure floats and monetary unions.

\section{The monetary model with distortions}

\subsection{The model}

We derive a variant of the monetary model in a two-country two-period endowment economy as presented in for example Stockman (1980) and Lucas (1982) to illustrate the relationship between fundamentals and the exchange rate. In contrast to these authors, we do not employ Clower's cash-in-advance-constraint but include money in the utility function. Both approaches have materially the same economic implications, but we deemed the latter more expedient. For simplicity only a two-period economy is considered. The novelty in our presentation relates to the incorporation of distortions which drive a wedge between the exchange rate and the standard fundamentals. We show how these may pick up the volatility in the fundamentals.

In the following foreign variables are superscripted by a star. There is uncertainty regarding the second period, and there are $n$ different states of the world $j$. The variables subscripted by $j$ thus refer to second period variables in state $j$. The domestic representative agent maximizes the following two-period time separable logarithmic expected utility function ${ }^{3}$

\footnotetext{
${ }^{3}$ Using a somewhat more general specification of power utility would not affect the derivation of the monetary model below, except for an extra constant.
} 


$$
E U=\ln X+\gamma \ln \frac{M}{\omega S P^{*}}+\beta \sum_{j=1}^{n} \pi_{j}\left\{\ln X_{j}+\gamma \ln \frac{M_{j}}{\omega_{j} S_{j} P_{j}^{*}}\right\}
$$

The utility function comprises a per period consumption bundle $X$ and real money balances $M / \omega S P^{*}$. The personal rate of time preference is the factor $\beta$. The $j$-th future state of nature carries probability $\pi_{\mathrm{j}}, \sum \pi_{\mathrm{j}}=1$. To save on notation we immediately express the domestic deflator into the foreign deflator. Thus the domestic price deflator $P$ of the nominal money balances $M$ equals the price of the consumption bundle in foreign prices $P^{*}$ times the trade distortion $\omega$ and the exchange rate $S$, i.e. $P=\omega S P^{*}$. The factor $\omega$ signifies the tariff levies, export subsidies, transportation costs and the tariff equivalent of any quotas that drive a wedge between the foreign and domestic price levels. This wedge is responsable for the absence of absolute PPP, see Obstfeld and Rogoff (2000).

The expected utility function is maximized subject to two budget constraints. The first period budget constraint reads

$$
0=\omega S P^{*}(X-Y)+B+\tau S D+M+T .
$$

Here $Y$ is the agent's endowment (production is exogenous), $B$ are domestic bonds, $D$ are foreign bonds, $M$ are money balances and $T$ are net transfers to the government. Since output $Y$ is exogenous, we only model net trade. We also do not explicitly model the demand for government services (these could be subsumed additively into the utility function). The government services are financed out of the lump sum tax, $T$, and changes in the money supply. The transfer $T$ may also comprise balance of payments support received from (subsidy given to) the other country via the IMF. Government accounting also comprises the revenues from tariff levies and capital controls. Domestic bonds trade at unit price and yield a gross return of $R$. Foreign bonds also trade at unit price abroad yielding $I$, but there may be a (non-unitary) capital control $\tau$ which distorts the trade in foreign securities (this is interpreted as the tariff equivalent of capital controls). The second period budget constraint in state $j$ is

$$
R B+\tau_{j} S_{j} I D+M=\omega_{j} S_{j} P_{j}^{*}\left(X_{j}-Y_{j}\right)+M_{j}+T_{j} .
$$

The left hand side records total returns from the first period investments in assets, while the right hand side gives net expenditures and money balances held for transaction purposes. Maximization entails solving the Lagrangian problem

$$
\begin{gathered}
\max _{X, M, B, D, X_{j}, M_{j}} L=E U+ \\
\lambda\left\{-\omega S P^{*}(X-Y)-B-\tau S D-M-T\right\}+ \\
\sum_{j=1}^{n} \pi_{j} \lambda_{j}\left\{R B+\tau_{j} S_{j} I D+M-\omega_{j} S_{j} P_{j}^{*}\left(X_{j}-Y_{j}\right)-M_{j}-T_{j}\right\} .
\end{gathered}
$$

The first order conditions (assuming non-corner solutions and sufficiency) with respect to $X, M$, $X_{j}, M_{j}, B, D$, are respectively 


$$
\begin{gathered}
\frac{1}{X}-\lambda \omega S P^{*}=0, \\
\frac{\gamma}{M}-\lambda+\sum_{j=1}^{n} \pi_{j} \lambda_{j}=0, \\
\frac{\beta}{X_{j}}-\lambda_{j} \omega_{j} S_{j} P_{j}^{*}=0, \text { for all } j, \\
\frac{\beta \gamma}{M_{j}}-\lambda_{j}=0, \text { for all } j, \\
-\lambda+R \sum_{j=1}^{n} \pi_{j} \lambda_{j}=0, \\
-\tau S \lambda+I \sum_{j=1}^{n} \pi_{j} \lambda_{j} \tau_{j} S_{j}=0,
\end{gathered}
$$

and the two budget constraints (2.2) and (2.3). Substituting (2.5) and (2.7) into (2.9) gives the consumption pricing kernel

$$
\beta R E\left[\frac{\omega S P^{*} X}{\omega_{j} S_{j} P_{j}^{*} X_{j}}\right]=1,
$$

and similarly, substituting (2.5) and (2.7) into (2.10) gives

$$
\beta I \mathrm{E}\left[\frac{\omega S P^{*} X}{\omega_{j} S_{j} P_{j}^{*} X_{j}} \frac{\tau_{j} S_{j}}{\tau S}\right]=1 .
$$

The monetary pricing kernels derive from combining (2.6) and (2.8) with (2.9)

$$
\beta(R-1) \mathrm{E}\left[\frac{M}{M_{j}}\right]=1,
$$

similarly using (2.6) and (2.8) and (2.10) gives

$$
\beta \frac{I}{R}(R-1) \mathrm{E}\left[\frac{M}{M_{j}} \frac{\tau_{j} S_{j}}{\tau S}\right]=1 .
$$

These kernels can be solved further by using the general equilibrium market clearing conditions and the budget constraints of individuals and the governments.

Apart from these pricing kernels we can directly obtain a semi-reduced form quantity equation as follows. From (2.6) and (2.9)

$$
\frac{\gamma}{M}=\lambda\left(1-\frac{1}{R}\right)
$$

In combination with (2.5) this yields 


$$
M\left(1-\frac{1}{R}\right)=\gamma \omega S P^{*} X
$$

The velocity term, $1-1 / R$, increases with $R$, and, when multiplied by money balances, equals nominal consumption expenditures scaled by the weight of money in the utility function. Note that the expenditures include the trade distortion.

In the foreign country the representative agent is assumed to solve a similar problem. The utility function of the foreign representative agent reads

$$
E U^{*}=\ln X^{*}+\gamma \ln \frac{M^{*}}{\omega^{*} P^{*}}+\beta \sum_{j=1}^{n} \pi_{j}\left\{\ln X_{j}^{*}+\gamma \ln \frac{M_{j}^{*}}{\omega_{j}^{*} P_{j}^{*}}\right\} .
$$

The Lagrangian reads

$$
\begin{gathered}
\max _{X^{*}, M^{*}, B^{*}, D^{*}, X_{j}^{*}, M_{j}^{*}} L^{*}=E U^{*}+ \\
\lambda^{*}\left\{-\omega^{*} P^{*}\left(X^{*}-Y^{*}\right)-\frac{1}{\tau^{*} S} B^{*}-D^{*}-M^{*}-T^{*}\right\}+ \\
\sum_{j=1}^{n} \pi_{j} \lambda_{j}^{*}\left\{\frac{R}{\tau_{j}^{*} S_{j}} B^{*}+I D^{*}+M^{*}-\omega_{j}^{*} P_{j}^{*}\left(X_{j}^{*}-Y_{j}^{*}\right)-M_{j}^{*}-T_{j}^{*}\right\} .
\end{gathered}
$$

From the corresponding first order conditions we obtain the following four pricing kernels

$$
\begin{gathered}
\beta I \mathrm{E}\left[\frac{\omega^{*} P^{*} X^{*}}{\omega_{j}^{*} P_{j}^{*} X_{j}^{*}}\right]=1, \\
\beta R \mathrm{E}\left[\frac{\omega^{*} P^{*} X^{*}}{\omega_{j}^{*} P_{j}^{*} X_{j}^{*}} \frac{\tau^{*} S}{\tau_{j}^{*} S}\right]=1, \\
\beta(I-1) \mathrm{E}\left[\frac{M^{*}}{M_{j}^{*}}\right]=1, \\
\beta \frac{R}{I}(I-1) \mathrm{E}\left[\frac{M^{*}}{M_{j}^{*}} \frac{\tau^{*} S}{\tau_{j}^{*} S_{j}}\right]=1 .
\end{gathered}
$$

As before, we can also derive the foreign quantity equation

$$
M^{*}\left(1-\frac{1}{I}\right)=\gamma \omega^{*} P^{*} X^{*}
$$

\subsection{Exchange rate implications}

By dividing the two quantity type equations (2.16) and (2.23)

$$
\frac{\gamma \omega S P^{*} X}{\gamma \omega^{*} P^{*} X^{*}}=\frac{M\left(1-\frac{1}{R}\right)}{M^{*}\left(1-\frac{1}{I}\right)}
$$


a monetary model of the exchange rate can be derived. Rearranging this expression we obtain

$$
S=\frac{M}{M^{*}} \frac{X^{*}}{X} \frac{\left(1-\frac{1}{R}\right)}{\left(1-\frac{1}{I}\right)} \frac{\omega^{*}}{\omega}
$$

The logarithmic form of (2.25) reads (using lower case letters to denote logarithmically transformed variables)

$$
s=\left(m-m^{*}\right)-\left(x-x^{*}\right)+\ln \frac{\left(1-\frac{1}{R}\right)}{\left(1-\frac{1}{I}\right)}-\ln \left(\omega-\omega^{*}\right) .
$$

Using shorthand notation, we write this equation in relative differences as

$$
s=\tilde{m}-\tilde{x}+\tilde{r}-\tilde{\omega} .
$$

Without the trade distortions measure, $\tilde{\omega}$, we would have a standard monetary approach exchange rate equation. Except that we obtain a somewhat different expression for the interest differential than in the usual Cagan velocity-based setup. Note that nevertheless

$$
d \ln \left(1-\frac{1}{R}\right) / d R=\frac{1}{R(R-1)}>0,
$$

so that an increase in the domestic interest rate depreciates the currency. Another minor difference is that we have expenditure, $x$, rather than income as the scale variable in the exchange rate equation. The specification (2.27) without the trade distortion also matches the specification of the macro-economic fundamentals as in Flood and Rose (1999, p. 663). Omitting $\tilde{r}-\tilde{\omega}$ from (2.27) gives the so-called traditional fundamental from Flood and Rose (1995).

Note the trade distortion measure in (2.27) enters with a negative sign, as in the case of the expenditure measure $\tilde{x}$. In principle, if these distortions are adjusted in the right way, they can compensate for the fluctuations in the other driving factors $\tilde{m}, \tilde{x}$ and $\tilde{r}$. How can we ensure that the $\omega$ and $\omega^{*}$ are chosen correctly? If these terms represent tariffs and subsidies, such a task might be impossible. If, however, they are taken to represent the implicit price distortions induced by a quota, then the case for variable adjustment in the distortions compensating such that the spot rate is constant appears reasonable.

Substituting the monetary pricing kernels (2.14) and (2.22) into (2.25) yields a relation between the goods and capital market distortions

$$
\frac{\omega X}{\omega^{*} X^{*}}=\frac{\tau R}{\frac{1}{\tau^{*} S} I} \frac{\mathrm{E}\left[\frac{1}{M_{j}^{*}} \frac{1}{\tau_{j}^{*} S_{j}}\right]}{\mathrm{E}\left[\frac{1}{M_{j}} \frac{1}{\tau_{j} S_{j}}\right]} .
$$

Absent foreign exchange market intervention, the capital account is the mirror image of the trade account, and hence $\omega$ and $\omega^{*}$ should be related to $\tau$ and $\tau^{*}$. The relationship is slightly more 
complicated due to the fact that capital account variables not only relate to current variables, but also to future variables. This is signified by the last factor in the expression which also contains future capital market distortions.

Another useful linkage to the extant literature can be made if we assume that the forcing variables are lognormally distributed. Using (2.12) and (2.19) into (2.25) gives

$$
S=\frac{M}{M^{*}} \frac{1-\frac{1}{R}}{1-\frac{1}{I}} \frac{\mathrm{E}\left[\frac{1}{P_{j}^{*} X_{j}} \frac{\tau_{j}}{\tau \omega_{j}}\right]}{\mathrm{E}\left[\frac{1}{P_{j}^{*} X_{j}^{*}} \frac{1}{\omega_{j}^{*}}\right]} .
$$

Furthermore, combine this with kernels (2.13) and (2.21) to obtain

$$
S=\frac{I}{R} \frac{\mathrm{E}\left[\frac{1}{M_{j}^{*}}\right]}{\mathrm{E}\left[\frac{1}{M_{j}}\right]} \frac{\mathrm{E}\left[\frac{1}{P_{j}^{*} X_{j}} \frac{\tau_{j}}{\tau \omega_{j}}\right]}{\mathrm{E}\left[\frac{1}{P_{j}^{*} X_{j}^{*}} \frac{1}{\omega_{j}^{*}}\right]} .
$$

The current exchange rate is now written in terms of expected future fundamentals. Adding the assumption that the future money stocks, the expenditures and distortions are jointly lognormally distributed yields a specification in the spirit of Hodrick (1989)

$$
s=\mathrm{E}\left[m_{j}-m_{j}^{*}\right]-\mathrm{E}\left[x_{j}-x_{j}^{*}\right]+\ln \frac{R}{I}-\ln \left(\tau \frac{\tau^{*} \omega^{*}}{\omega}\right)+\mathrm{E}\left[\ln \tau_{j}+\ln \omega_{j}^{*}-\ln \omega_{j}\right]+\Omega .
$$

Here $\Omega$ is the risk premium comprising the sum of variances and covariances of the individual variables

$$
\begin{gathered}
=\frac{1}{2}\left\{\left[\sigma_{m_{j}^{*}}^{2}-\sigma_{m_{j}}^{2}\right]+\right. \\
{\left[\sigma_{x_{j}}^{2}+\sigma_{\ln \tau_{j} / \omega_{j}}^{2}+2 \sigma_{p_{j}^{*}, x_{j}}-2 \sigma_{p_{j}^{*}, \ln \tau_{j} / \omega_{j}}-2 \sigma_{x_{j}, \ln \tau_{j} / \omega_{j}}\right]} \\
\left.-\left[\sigma_{x_{j}^{*}}^{2}+\sigma_{\ln \omega_{j}^{*}}^{2}+2 \sigma_{p_{j}^{*}, x_{j}^{*}}+2 \sigma_{p_{j}^{*}, \ln \omega_{j}^{*}}+2 \sigma_{x_{j}^{*}, \ln \omega_{j}^{*}}\right]\right\} .
\end{gathered}
$$

The interesting aspect of this specification is that it comprises both capital market and trade distortions. In sum, we have several variants of the monetary model including distortions. In the absence of distortions, the specifications reduce to the standard monetary models from the literature.

To make a link to the empirical sections, consider again (2.27). Compute the variance on both sides of this equation

$$
\begin{aligned}
\sigma_{s}^{2}= & \sigma_{\tilde{m}}^{2}+\sigma_{\tilde{x}}^{2}+\sigma_{\tilde{r}}^{2}+\sigma_{\tilde{\omega}}^{2} \\
& -2 \sigma_{\tilde{m}, \tilde{x}}+2 \sigma_{\tilde{m}, \tilde{r}}-2 \sigma_{\tilde{m}, \tilde{\omega}}-2 \sigma_{\tilde{x}, \tilde{r}}+2 \sigma_{\tilde{\tilde{x}}, \tilde{\omega}}-2 \sigma_{\tilde{r}, \tilde{\omega}} .
\end{aligned}
$$

Without variability in the distortions, i.e under a free float, the volatility reduces to 


$$
\begin{aligned}
\sigma_{s}^{2}= & \sigma_{\tilde{m}}^{2}+\sigma_{\tilde{x}}^{2}+\sigma_{\tilde{r}}^{2} \\
& -2 \sigma_{\tilde{m}, \tilde{x}}+2 \sigma_{\tilde{m}, \tilde{r}}-2 \sigma_{\tilde{x}, \tilde{r}} .
\end{aligned}
$$

In a fixed exchange rate regime, (2.34) becomes

$$
\begin{aligned}
0= & \sigma_{\tilde{m}}^{2}+\sigma_{\tilde{x}}^{2}+\sigma_{\tilde{r}}^{2}+\sigma_{\tilde{\omega}}^{2} \\
& -2 \sigma_{\tilde{m}, \tilde{x}}+2 \sigma_{\tilde{\tilde{m}}, \tilde{r}}-2 \sigma_{\tilde{m}, \tilde{\omega}}-2 \sigma_{\tilde{\tilde{x}}, \tilde{r}}+2 \sigma_{\tilde{x}, \tilde{\omega}}-2 \sigma_{\tilde{r}, \tilde{\omega}}
\end{aligned}
$$

The terms $\sigma_{\tilde{\omega}}^{2}-2 \sigma_{\tilde{m}, \tilde{\omega}}+2 \sigma_{\tilde{x}, \tilde{\omega}}-2 \sigma_{\tilde{r}, \tilde{\omega}}$ can compensate for the volatility in the fundamentals, effectively driving the exchange rate variability $\sigma_{s}^{2}$ to zero. Under a dirty float, all terms in (2.34) will in general be non-zero. The next sections try to identify the missing variances and covariances.

\section{Inter-regime volatility}

In this section we combine data from the Bretton Woods and post-Bretton Woods periods to address the issue of the importance of the wedge in explaining why traditional monetary fundamentals may not be enough to explain inter-regime volatility. Representative candidates for the wedges as in (2.27) and (2.32) for the Bretton Woods period are official reserves, IMF support and capital controls. We start by examining the role of IMF support in surpressing exchange rate variability during the Bretton Woods period. We then go on to combine IMF support with traditional fundamentals, like money and income, to address the volatility issue. The volatility comparisons will be done using both annual and monthly datasets. Both datasets span the Bretton Woods and post-Bretton Woods periods and for European currencies include the period in which the ERM operated. This variation in regimes within the dataset follows Flood and Rose (1995) and is essential for an empirical investigation of inter-regime volatility. Throughout the empirical analysis, two countries will be used as numeraire: the United States (1) and Germany (2). Although the US was clearly the dominant numeraire currency in the Bretton Woods period, Germany's importance increased in the post-Bretton Woods period, particularly after the formation of the ERM. Finally, a case study of the UK illustrates the role of capital controls and the IMF support in breaking the link between the exchange rate and fundamental volatility.

\subsection{Reserves, IMF support and exchange rate volatility}

In this section we look more closely at the role of reserves and IMF support in explaining the volatility disconnect in fixed exchange rate periods. We look first at the appropriate way to measure reserves and then go on to illustrate the quantitative importance of IMF support.

To the extent that central banks use foreign exchange reserves to stabilize the exchange rate, a tradeoff between exchange rate and reserve volatility would be expected. According to the monetary approach to the balance of payments, a divergence in the fundamentals (e.g. high domestic money growth) must be dissipated through a loss of reserves or the peg will have to be 
abandoned. Note, however, that we do not expect such a trade-off when the fundamentals do not diverge.

There appears to be little in the way of empirical evidence supporting a trade-off between exchange rate and reserve volatility. Intuitively, the abandonment of a peg would be expected to lead to a reduction in reserve holdings and their volatility. However, Flood and Rose (1995) find that the volatility of reserves is generally higher following the collapse of the Bretton Woods system. We offer an explanation for this apparent absence of a tradeoff. A key reason why there may not be a stronger trade-off between reserves and exchange rate volatility is because IMF credit facilities can distort the relationship. In this section we argue that any analysis of the tradeoff between exchange rate and reserve volatility needs to take into account the role of IMF credit in supporting weak currencies.

In Table 1 we illustrate the issue for the UK, a key participant in the Bretton Woods regime. Table 1 contains annual data for the UK from 1960 to 1969, a turbulent period in UK monetary history. Column 1 gives the IMF quota. We note that when Fund holdings of sterling (column 4) are below the quota, the UK's reserve position in the IMF (column 3) is positive and equals the difference between the two series; otherwise the reserve position equals zero. Each time the UK drew upon the IMF, the IMF's total holdings of sterling increased, leading to a reduction in the UK's reserve position at the Fund. When the reserve position reached zero, fund credit (column 2) allowed further drawings to levels above the quota. Non-gold reserves (column 6) equal the foreign exchange reserves (column 5) plus the UK's reserve position in the fund (column 3). In times of crisis, such as in 1961 and from 1964 onwards, the UK borrowed money from the IMF to replenish its foreign reserves. During 1965-1966 the extensive use of Fund credit may have postponed sterling's devaluation to November 1967. This is not at all clear from the data on foreign exchange reserves or non-gold reserves. These are low in 1964, but not thereafter since these data do not discriminate between reserve increases resulting from improvements in the balance-of-payments or from Fund borrowings! Hence, it would seem that the existence of IMF credit distorts reserve data. This cautions against using the standard reserve data in a volatility calculation and suggests that accounting for IMF support will give a better picture of the volatility trade-off.

We therefore look at whether IMF support is quantitatively important enough to include in an analysis of the volatility tradeoff. Table 1 shows that during the 1960s, Fund holdings of sterling were large compared to foreign exchange or non-gold reserves. Additionally, Table 2 shows the IMF's holdings of currency as a percentage of non-gold reserves for all countries during three subperiods. In general this percentage is highest during the Bretton Woods years and in the 1970s. With a few exceptions the percentage has declined from the 1980 s onwards. ${ }^{4}$

In the remainder of our analysis of inter-regime volatility we look at the IMF holdings of a currency as a percentage of its IMF quota, to correct for the effect of quota increases. In their analyses of the volatility trade-off, Flood and Rose (1995) examined if the existence of non-gold

\footnotetext{
${ }^{4}$ In Table 2, the high percentage for France during the first sub-period can be partly explained by the fact that France had chosen to hold most of its reserves in gold instead of in foreign currency.
} 
reserves was an important source of fundamental volatility. They concluded it was not, but our discussion here suggests that it is not sufficient to rely on non-gold reserves, rather fund credit or fund holdings of currency should be taken into consideration. We thus opt for fund holdings of currency as a percentage of fund quota and refer to this as our IMF variable.

Figure 1 contains scatter plots of the change in the exchange rate (against the dollar, in dlog) versus, respectively, the change in our IMF variable (in dlog) in the top plot and the change in non-gold reserves (in dlog) in the bottom plot. The data are monthly and combine the experiences of 21 countries over the period 1960 to 19998 (see the data appendix for a list of countries). The scatter-plot for the IMF variable is shaped in the form of a cross, implying a highly non-linear dependence between changes in the exchange rate and the IMF measure. There thus exists a volatility tradeoff, though not a linear one. Either exchange rates or the Fund holdings of a currency are adjusting, but hardly ever are the two mechanisms for adjustment combined. In comparison, the scatterplot for non-gold reserves has much less observations along the axes, suggesting the absence of a similar non-linear tradeoff between changes in the exchange rate and non-gold reserves. Here the two adjustment mechanisms are repeatedly used in tandem, or even occur in such a way that one partly compensates the other.

Based on the UK experience during the 1960s, the magnitude of IMF support (especially in the Bretton Woods period) and the cross-shaped pattern in the top plot of Figure 1, we have chosen the IMF variable as our candidate measure of the wedge. In the next two sections, we combine the IMF variable with traditional fundamentals to estimate (2.34).

\subsection{Volatility comparisons: annual data}

As an initial pass at the issue of inter-regime volatility we present in Table 3 the variances of two traditional macroeconomic fundamentals, namely the annual inflation and income growth differentials, along with the change in the exchange rate and the change in our IMF support variable across 19 countries (see Table A1 in the data appendix for a listing of countries). The use of annual data has the advantage of reducing short-term noise in the macroeconomic data while preserving the main stylised facts. As this comes at the cost of a reduction in the number of observations, an analysis of monthly data is added in the next subsection. In the empirical analysis we use income growth instead of consumption growth. We have also chosen inflation instead of money supply growth as our monetary fundamental because of the limited availability of money growth data for several countries in the 1960s. This is an important consideration in view of the small sample size of our annual analysis. We will redress this in the monthly analysis below, which includes money growth. The variances in Table 3 have the US and Germany as their numeraire countries and are calculated for three subperiods of comparable length (a Bretton Woods period, from 1961 to 1971, and two post Bretton Woods periods, respectively from 1972 to 1983 and from 1984 to 1998).

The first point to note from these results is that they confirm the point made by a number of other researchers, that in moving from Bretton Woods to the post-Bretton Woods period the volatility of standard fundamentals is very similar but the volatility of the exchange rate changes substantially. Note, however, that in the floating periods exchange rate volatility vis-à-vis the 
dollar is almost twice the volatility vis-à-vis the DM. This suggests that the volatility issue might be at least partly a dollar issue. We will return to this theme below. The results in Table 3 also indicate that there is a lot of volatility stemming from the IMF variable in the Bretton Woods period and, interestingly, that the average volatility of this variable decreases as we move into the first post-Bretton Woods period and decreases substantially in the period when capital controls were finally relaxed (1984-1998). There thus appears to be a clear trade-off between $\Delta s$ volatility and $\triangle I M F$ volatility as one moves between regimes.

To explicate the inter-regime volatility we run regressions of exchange rate volatility on fundamental volatility as specified in equation (2.34). As we noted, under a fixed regime (2.34) collapses to (2.36), while in a undistorted free float (2.34) reduces to (2.35). If one has only data from these two pure regimes, a regression of $\sigma_{s}^{2}$ on fundamentals $\sigma_{\tilde{m}}^{2}, \sigma_{\tilde{\chi}}^{2}, \sigma_{\tilde{r}}^{2}$ and the wedge $\sigma_{\tilde{\omega}}^{2}$, gives a negative coefficient on the latter variable. The intuition for this is in Figure 1. Since under a pure float $\sigma_{s}^{2}=0$ and in a undistorted free float $\sigma_{\tilde{\omega}}^{2}=0$, the variances in both cases lie on a hyperplane of a dimension lower than if all variances are non-zero. One can show that this implies a negative sign on the $\sigma_{\tilde{\omega}}^{2}$ variable in a regression of exchange rate volatility on the volatilities of the fundamentals and the wedge. ${ }^{5}$ Since a fair number of observations comes from the dirty float period in the 1970s and we have ommitted variables, we do not expect a perfect correspondence between the theoretical specification in (2.34) and the empirical results.

In Table 4 we estimate equation (2.34) using the annual dataset by means of generalized least squares on the panel of 19 countries and for the 3 subperiods identified above. This yields a total of 57 observations. For both numeraire currencies, we report three different specifications, which differ depending on the inclusion of covariance terms and the IMF variable. Interest rates have been omitted from the regressions due to lack of data. Below, we will include interest rates in a smaller sample of monthly data. Table 4 yields some interesting observations. First, the explanatory power of the DM regressions is high compared to the results for the dollar. Whereas fundamentals explain over $50 \%$ of the variance of the exchange rate vis-à-vis the German currency, the explanatory power versus the dollar stays around 25\%. The second observation relates to the sign and significance of the traditional fundamentals. For the German numeraire, the variances of inflation and income growth are positively and significantly related to the variance of the exchange rate, as one would expect from the monetary model. Together these two variances can explain $56 \%$ of the variance in the DM exchange rate. Inflation and income growth do much worse in the dollar regressions, where the variance of inflation is barely significant and the variance of income has the wrong sign.

Turning to the variance and covariances involving the IMF variable, we observe that these are highly significant in the dollar regressions, but less so in the DM regressions. In all specifications, the variance of the IMF variable has a negative sign, as explained above. This corresponds to the visual impression from Figure 1, which illustrated the negative cross-shaped dependence between

\footnotetext{
${ }^{5}$ In regression terms, this is due to zeros in the X-matrix with the explanatory variables and in the y-vector with the dependent variable in particular places.
} 
the exchange rate and IMF support, and also makes intuitive sense, as fluctuations in IMF support might serve to stabilize the currency.

According to (2.34), volatility in IMF support should increase exchange rate volatility, ceteris paribus the volatility in other fundamental variables. It is only by covarying with the traditional fundamentals that IMF support should result in lower exchange rate volatility. A good example of how this works is the negative and significant coefficient of $\operatorname{covar}(\Delta \tilde{p}, \Delta I M F)$ in the dollar specification, which can be interpreted quite easily: inflationary policies in the Bretton Woods period could be sustained longer without the need for an exchange rate adjustment when IMF support was made available. A positive covariance between $\Delta \tilde{p}$ and $\Delta I M F$ thus reduces $\operatorname{var}(\Delta s)$. The negative sign of the coefficient of $\operatorname{var}(\triangle I M F)$ has been explained in regression terms above. In addition, inflation and income may inadequately capture fundamental volatility. The significant negative sign for $\operatorname{var}(\Delta I M F)$ may then pick up the covariances between IMF support and other missing fundamental variables. Candidates for such missing variables are, for example, fiscal policy variables and the current account.

Summarizing our annual results, we conclude that the extent to which the volatility issue is a puzzle seems to depend on the choice of numeraire. The traditional fundamentals do well in the DM regressions, but badly in the dollar regressions. In addition, our IMF variable adds explanatory power to both the dollar and DM regressions. We will now investigate whether these results are upheld using a monthly dataset.

\subsection{Volatility comparisons: monthly data}

We use monthly data to derive annual standard deviations (based on 12 non-overlapping monthly observations) as our volatility measures. These are calculated only for complete years (i.e. years for which we have 12 monthly observations). In principle, this yields 39 (years) times 21 (countries) $=819$ observations, but in practice limited data availability reduced this number, see the bottom line of Table 5. For all variables, except IMF support, we take the first differences of the logs relative to the numeraire. See the data appendix for full details.

Table 5 reports regression results for a large sample including all countries except Switzerland (for which the IMF measure was unavailable for most of the sample period). Due to the limited data availability for many countries, this regression again excludes interest rate volatility, but we can now use money growth instead of inflation. Table 5 shows that the variance of money growth is significantly related to exchange rate volatility in all specifications. Income volatility is unrelated to exchange rate volatility in all regressions. Similar to the annual results, the volatility connection holds better versus Germany than versus the US, both in terms of significance and explanatory power. For both numeraires, the coefficient of $\operatorname{cov}(\Delta \tilde{m}, \Delta I M F)$ is significantly negative, implying that IMF support can reduce or postpone the spill-over of a relatively high money growth into exchange rate volatility. This result resembles the significance of $\operatorname{cov}(\triangle \tilde{p}, \Delta I M F)$ in the annual dollar regressions. It supports our interpretation of IMF support as driving a wedge between the volatility in traditional fundamentals and exchange rate volatility. In addition to the covariance term, $\operatorname{var}(\triangle I M F)$ is significantly negative in the DM regressions. This 
also corresponds to the annual results (see the previous section for explanations for the negative sign of the coefficient of $\operatorname{var}(\triangle I M F))$.

In order to ensure that our regression results do not depend on the inclusion of small highinflation countries, Table 6 reports the results of a balanced panel regression for six large industrialized countries (Canada, France, Italy, Australia, the UK and either the US or Germany). Note that the number of observations is much lower than in the full monthly dataset. This set of results shows the starkest contrast between the two numeraires. While the dollar regressions fail, overall, to establish a link between fundamental volatility and exchange rate volatility (except for the covariance term between money and income growth), the DM regressions are much stronger. All variances except $\operatorname{var}(\Delta \tilde{y})$ are significantly related to $\operatorname{var}(\Delta s)$, including the variance of the long-term interest rate $(\operatorname{var}(\Delta i l))$. In addition, three out of six covariance terms are significant at at least a $10 \%$ level. Given the self-imposed constraint of a cross-section limited to just six countries, this is a strong result.

We conclude that the monthly data confirm the annual results. The fundamental connection is strongest in regressions which take the DM as the numeraire currency. In the majority of the regressions, there also appears to be a role for IMF support in explaining the wedge between fundamental and exchange rate volatility. Having said that, the explanation of currency volatility vis-à-vis the dollar remains a challenge.

\subsection{A case study of inter-regime volatility}

In this subsection we investigate the volatility disconnect puzzle in more detail for one country, namely the United Kingdom. We use monthly data over the period 1960-1998 and take Germany as the numeraire country. One of the key reasons for focusing on this country is that we have access to good quality data on the onshore-offshore differential for the Bretton Woods and the post Bretton Woods period, and can therefore make an inter-regime comparison of volatility using this wedge variable. Figure 2 combines four time-series graphs which, in our view, together, present a coherent picture of the connection between exchange rate and fundamental volatility for the United Kingdom. The graphs plot absolute percentage changes in the pound/DM rate, absolute changes in the off-shore/on-shore interest rate differential (annualized yields), designed to get at the issue of the importance of capital controls, absolute money growth differentials versus Germany and absolute percentage changes in IMF holdings of sterling.

Three subperiods can be distinguished here. In the first, during the 1960s, the fixed peg prevented fundamental volatility from spilling over into immediate exchange rate volatility, although the pound sterling devalued twice during this period. The second period is the 1970s, where the exchange rate becomes flexible and money growth volatility increases strongly. In this period, a strong divergence between the fundamentals of the UK and Germany leads to both a high level of exchange rate volatility and volatility in the capital control and IMF support terms. We hypothesize that absent capital controls and IMF support, exchange rate volatility would have been even higher in this period. In the third period, starting at the beginning of the 1980s, capital controls and IMF support lose their role in UK policy and we start to see a straightforward 
relationship between fundamental and exchange rate volatility, undistorted by IMF support and capital controls. It is striking how marked the difference is between the first and third subperiods. The volatility of the onshore/offshore differential is almost the reverse of the stylised exchange rate volatility - highly volatile in Bretton Woods and hardly any volatility in the last floating rate period. This would seem to underscore the predictions of our model that previous discussions of the volatility trade off have missed a key variable for the Bretton Woods period. Note also that the volatility of IMF support is also important for the Bretton Woods period but almost nonexistent in the last floating rate period.

\section{Intra-regime volatility}

The second part of our empirical investigation looks at the issue of intra-regime volatility. We focus first on two flexible exchange rate regimes, the inter-war experience and the post-Bretton Woods regime. We then go on to examine the the ERM experience of target zones with adjustable exchange rates, which highlights the important role that capital controls can have in driving a wedge between exchange rate volatility and fundamental volatility. Finally, we examine how fundamentals behave in two monetary unions: the EMU and the US.

\subsection{The interbellum experiences and the post-Bretton Woods period}

In this subsection we re-examine whether exchange rates are excessively volatile in two flexible foreign exchange regimes, namely the inter-war floating exchange rate experience and the postBretton Woods period. We show that there is quite a close correspondence between exchange rate volatility and fundamental volatility. The issue of intra-regime volatility is perhaps not quite as contentious as that of inter-regime volatility. This is illustrated in the work of Flood and Rose (1995) who demonstrated for the post-Bretton Woods period that there is quite a tight link between the volatility of so-called virtual (that is the log of the exchange rate minus the interest differential scaled by the interest rate semi-elasticity of the demand for money) and traditional fundamentals (the sum of the log differentials of money and income). Indeed, the two series appear to be indistinguishable.

Our own data sets essentially confirm the findings of Flood and Rose. Consider, first, our base line monetary model, the version of the model without the wedge generated by the distortions. The inter-war results are presented in Table 7. Due to German hyperinflation the choice of numeraire has been confined to the US. Because of data limitations income volatility is not included in Table 7. Nonetheless, even without income volatility, it is clear that money growth volatility closely mirrors exchange rate volatility. In some cases where exchange rate volatility is substantially higher than money growth volatility (e.g. Belgium, Finland and France), the mean money growth differential is high, indicating monetary divergence between these countries and the US. In the bottom rows of Table 7 we report rank correlations which have been calculated to account for the extreme observations due to the hyperinflations in Austria and Germany. These show a significant link between the standard deviations of the exchange rate and money growth and between mean money growth and exchange rate volatility. 
In Table 8 we present descriptive statistics for the post-Bretton Woods period. We report standard deviations of log differences of the exchange rate and fundamentals, with both the US and Germany as alternate numeraires. We note, first, the strikingly close correspondence between the average fundamental volatility and the volatility of the exchange rate, reported in the final row of the table. The close correspondence between exchange rate and fundamental volatility is also evident on a country-by-country comparison. It is noteworthy that with the US as numeraire in 9 cases exchange volatility (just) dominates fundamental volatility, while in 7 cases the opposite is actually true. With Germany as the numeraire currency, the score runs in the opposite direction 11 versus 10. In sum, Table 8 shows the quite striking result that the order of magnitude of volatility in total fundamentals from the base-line monetary model $(m-y)$ is not very different from that in changes of the exchange rate. Although the order of magnitudes of the standard deviations reported in Table 8 are similar, the correlation between fundamental volatility and exchange rate volatility across countries turned out to be insignificant (these are not reported).

We conclude that researchers who have inferred that exchange rates are excessively volatile in these regimes may have misinterpreted the data.

\subsection{Target zones}

In this section we examine the volatility of fundamentals and exchange rates during the Exchange Rate Mechanism (ERM) of the European Monetary System. Evidence from the ERM highlights the role of capital controls acting as a wedge to disconnect exchange rate volatility and fundamental volatility in the short term (see also Gros and Thygesen, 1998). Evidence from the monetary unions in the US and Germany serves to show that fundamentals are closely aligned when the exchange rate is never allowed to vary.

Table 9 presents data on exchange rate and fundamental volatility for France, Italy and the Netherlands during three subperiods of the ERM: the turbulent starting period from 1979 to March 1983, the period of tranquility in the EMS from April 1983 to the 1992 crisis and, finally, the period from the EMS crisis to the start of EMU. The classification into these three subperiods follows Gros and Thygesen (1998). For each country we provide standard deviations of the exchange rate with realignments $(\Delta s)$ and without such realignments ( $\Delta s$ excl. realignments), along with the standard deviations of the composite fundamental term and the offshore/onshore interest differential. There are a number of observations that we draw from this table.

First, the magnitude of exchange rate volatility is clearly dependent on whether realignments are excluded or not. With realignments included, exchange rate volatility is much greater compared to the nonrealignment position. It is noteworthy that in their calculation of Virtual Fundamentals Flood and Rose (1995) do not include exchange rate realignments for the Bretton Woods period and this must bias their findings in favor of the volatility of fundamentals dominating the volatility of the exchange rate.

The second point we note from Table 9 is that for France and Italy, mean growth rates in fundamentals versus Germany deviated strongly in the first subperiod ( $\mu$ equals respectively 0.47 and 0.89$)$ compared to the other two subperiods $((\mu<0.25$ in all cases $)$, while the standard 
deviations are similar across periods. It would thus appear that the differences in the means are more related to the unrest in the ERM than the differences in the standard deviations. For the Netherlands, the mean growth in fundamentals is very similar to Germany across the three periods and there is corresponding lower volatility in the exchange rate and the off-shore/onshore interest rate differential in the three periods. We believe this observation makes economic sense: when fundamentals between countries are on stable but diverging paths, currency markets will react to this.

The third interesting aspect of Table 9 is that volatility in the change in the off-shore/on-shore interest rate differential is important for France and Italy during the subperiod when capital controls were in force (i.e. 79.01-83.03). The standard deviations of the interest rate differential equaled 0.31 and 0.30 for France and Italy, respectively, before dropping to levels below 0.10 in the final two subperiods. Clearly, the existence of capital controls for prolonged periods, such as during the Bretton Woods regime, could explain the disconnect between the volatility of fundamentals and exchange rates. Since the Netherlands was, in general, pursing monetary policies which were consistent with the Bundesbank during much of the ERM experience capital controls were less important, as the final row in Table 9 illustrates.

\subsection{Monetary unions}

We now finally discuss data on fundamental volatility in regions where the exchange rate is not allowed to adjust. According to the monetary model discussed in section 2, we would expect fundamental volatility to be much lower between these regions compared to fundamental volatility between regions with separate currencies. This is not only because the exchange rate can no longer provide adjustment (either continuously in a float or periodically in a fixed but adjustable exchange rate regime), but also because our wedge variables typically do not play a role within monetary unions.

Table 10 combines data on 10 European countries and 9 German provinces for the period 19901998. The largest German province - Nordrhein Westfalen - is used as the numeraire. In this way we can compare the experience within the monetary union with the experiences outside Germany. The lower part of Table 10 shows that even within Germany, some fundamental volatility exists, though the order of magnitude is smaller than the fundamental volatility that exists between the European countries. Especially the volatility in the inflation differential is much lower for the German provinces than for the European countries. Exchange rate volatility for the European countries appears to be highest when there is either real divergence (i.e. for Ireland and Finland) or monetary divergence (i.e. Greece). The correlation coefficients at the bottom of Table 10 show that there is a statistically significant relationship between the standard deviation of $\Delta s$ and the standard deviations of $\Delta \tilde{p}, \Delta \tilde{m}$ and $\Delta \tilde{y}$.

We finally consider data from the US monetary union. Figures 3 and 4 show the synchronous movement in fundamentals - demand deposits and income - in the US monetary union during the long period from 1929 to 1983. The deviation of demand deposit growth in New York from the national pattern - especially during the 1940s - can be attributed to New York's role as a financial center. Apart from the demand deposits in New York, the cross-state correlations between 
fundamental growth rates are extremely high (always higher than 0.80), which is what one would expect in a monetary union. We conclude that the data for monetary union fit the monetary model very well: when the exchange rate is not allowed to adjust, fundamental volatility will need to adjust downwards. This is an obvious potential future test for the performance of EMU. Atpresent, the short period since the introduction of the euro makes it hard to empirically assess whether a divergence of fundamentals will lead to a collapse of the union or whether the fundamentals are indeed slowly converging.

\section{Conclusions}

There exists a widely held notion that freely floating exchange rates are excessively volatile when judged against traditional macroeconomic fundamentals and when moving from fixed to floating exchange rates. In this paper we have reexamined the issues of inter- and intra-regime volatility using a number of different data sets. In terms of the issue of inter-regime volatility, we have confirmed the findings of a number of other researchers that in moving from fixed to floating exchange rates the variability of the standard macroeconomic fundamentals stays roughly unchanged, but what does change is the volatility of the exchange rate (both real and nominal). However, in contrast to other studies we have demonstrated both theoretically and empirically that there may be other factors, reflected in what we call the wedge, that help to explain why fundamentals are not sufficiently volatile in fixed exchange rate regimes. In particular, we have shown that capital controls and a country's position at the IMF are important sources of volatility, or suppressed volatility. In sum, we argue, and indeed demonstrate, that in cross-regime comparisons one has to account for the missing variables which compensate for the fundamental variables volatility under fixed rates. Moreover, we find that the volatility issue may be partly a dollar issue, as the link between fundamental volatility and exchange rate volatility improves markedly if we switch the numeraire from the dollar to the DM.

Our analysis of intra-regime volatility shows, inter alia, that it is important to include exchange rate realignments in any calculation of exchange rate volatility in fixed exchange rate regimes; this point seems to have been ignored in previous empirical studies. We also demonstrate that in flexible exchange rate regimes there is actually quite a close link between exchange rate volatility and fundamental volatility using standard macroeconomic variables. It would seem therefore that what many regard as a stylised fact of floating rate regimes - that exchange rates are excessively volatile - is something of a mirage. 


\section{References}

Baxter, M. and A. Stockman (1989), Business cycles and the exchange rate regime: some international evidence, Journal of Monetary Economics, 23, 3, 377-400.

Duarte, M. (2003), Why don't macroeconomic quantities respond to exchange rate variability, Journal of Monetary Economics, 50, 889-913.

Flood, R. and A. Rose (1995), Fixing exchange rates: a virtual quest for fundamentals, Journal of Monetary Economics, 36, 3-37.

Flood, R. and A. Rose (1999), Understanding exchange rate volatility without the contrivance of fundamentals, Economic Journal, 109, 660-672.

Frankel, J.A. and R. Meese (1987), Are exchange rates excessively variable?, S Fischer ed. NBER Macroeconomics Annual, Cambridge: MIT Press, pp 117-153.

Friedman, M. (1953), The case for flexible exchange rates, in: Essays in positive economics, Chicago: Chicago University Press, 157-203.

Gros, D. and N. Thygesen (1998), European monetary integration, Longman.

Hodrick, R.J. (1989) Risk, uncertainty and exchange rates, Journal of Monetary Economics 23, 3, 433-459.

Johnson, H.G. (1958), International trade and economic growth, Cambridge Mass: Harvard University Press.

Lucas Jr., R.E. (1982), Interest rates and currency prices in a two-country world, Journal of Monetary Economics 10, 335-359.

MacDonald, R. (1999), Exchange rate behavior: are fundamentals important?, Economic Journal, 109.

Mark N. and D. Sul (2001), Nominal exchange rates and monetary fundamentals: evidence from a small post-Bretton Woods panel, Journal of International Economics, 53, 1, 29-52.

Mulligan C.B. and X. Sala-i-Martin (1992), US money demand: surprising cross-sectional estimates, Brookings Papers on Economic Activity, 2, 285-343.

Obstfeld, M. and K. Rogoff (2000), The six major puzzles in international macroeconomics: is there a common cause?, in: B. Bernanke and K. Rogoff (eds), NBER Macroeconomics Annual, Cambridge: MIT Press, 339-390.

Reinhart, C.M. and K. Rogoff (2002), The modern history of exchange rate arrangements: a reinterpretation', NBER working paper 8963.

Sohmen, E. (1961), Flexible exchange rates, Chicago: Chicago University Press.

Stockman, A.C. (1980) A theory of exchange rate determination, Journal of Political Economy 88, 673-698. 


\section{Data appendix}

\section{Bretton Woods, Post-Bretton Woods and ERM}

The annual macro-economic data used in section 3.2 have been taken from the European Commission AMECO database, except the data on IMF support, which have been derived using data from the IFS cd-rom (see below). The following countries are included: Australia, Austria, Belgium, Canada, Denmark, Finland, France, Germany, Greece, Ireland, Italy, Japan, Netherlands, New Zealand, Norway, Portugal, Spain, Sweden, United Kingdom and the USA.

The monthly macro-economic data have been taken from the IFS cd-rom. The data are monthly and start in January 1960. Due to the introduction of the euro in January 1999, the sample period ends in December 1998. The following countries are included: Australia, Austria, Belgium, Canada, Denmark, Finland, France, Germany, Greece, Ireland, Italy, Japan, Korea, Netherlands, Norway, Portugal, South-Africa, Spain, Sweden, Switzerland, United Kingdom and the USA. Our exchange rate measure is the bilateral period-average price of the US $\backslash$ dollar (IFS line rf). We choose M1 (IFS line 34 or national definition) as our monetary aggregate. Where M1 was not available, we have chosen either a narrower (currency, IFS line 34A) or a broader aggregate (IFS line $35 \mathrm{M}$ or the national definition). To control for seasonality, we filter the money series by applying a one-sided moving average of the current observation and 12-lagged values (cf. Mark and Sul, 2001). The seasonally adjusted industrial production index (IFS line 66) is used for output; the CPI (IFS line 64) for prices. We use both long-term (IFS line 61) and short-term interest rates (IFS lines 60b/60c). Off-shore interest rates are available for a only few countries. Regarding reserves, we use non-gold reserves (IFS line 1L) and Fund holdings of domestic currency as a percentage of quota (IFS line 2F). The latter measure - denoted IMF - indicates the extent to which a country draws upon the IMF. Data on the exchange rate and non-gold reserves are available for all countries over the complete sample period. The same applies to the IMF measure, with the exception of Portugal (1962:7-1998:12) and Switzerland (1992:2-1998:12). The availability of other series is indicated in Table A1. All data have been checked and corrected for errors. With the exception of interest rates, the data are transformed by natural logarithms. Interest rates are measured as nominal rates divided by 1200 .

\section{Interbellum}

Data on exchange rates and money supplies are from the Bulletin Mesnuel de Statistique of the League of Nations.We are grateful to Martijn van Harten for collecting these data.

\section{EMU countries and German provinces}

Our exchange rate measure is the bilateral period-average price of the D-Mark, calculated from US dollar exchange rates (IFS line rf). Income and price are measured by respectively real GDP and the GDP deflator, available from the IFS (EMU countries) and the statistical office of the state of Baden-Württemberg (German provinces).We have chosen a broad monetary aggregate (M3/M2). For the EMU countries, data were available from Eurostat. Information on the regional distribution of currency within Germany is not available. Following Mulligan and Sala-i-Martin (1992), we proceeded using deposit data. For the German provinces, we use total deposits as our 
monetary aggregate. This aggregate includes sight deposits ("Sichteinlagen"), savings deposits ("Spareinlagen"), time deposits ("Termingelder") and the socalled "Sparbriefe", and corresponds closest to the M3 monetary aggregate. We are grateful to Dr. H. Herrmann from the Bundesbank for providing these data.

\section{US regions}

Data on demand deposits and real income for nine US regions (New England, Mideast, excluding New York, New York, Great Lakes, Plains, Rocky Mountains, Southeast, Southwest, Farwest) were kindly provided by Peter Ireland. 
Tables

Table 1: IMF Support for the United Kingdom during the 1960s

\begin{tabular}{l|rrrrrr}
\hline & $\begin{array}{c}\text { (1) } \\
\text { Quota }\end{array}$ & $\begin{array}{c}\text { Use of fund } \\
\text { credit }\end{array}$ & $\begin{array}{c}\text { ceserve } \\
\text { position }\end{array}$ & $\begin{array}{c}\text { Fund holdings } \\
\text { of sterling }\end{array}$ & $\begin{array}{c}\text { coreign } \\
\text { Fochange } \\
\text { excher }\end{array}$ & $\begin{array}{c}\text { (6) } \\
\text { Non-gold } \\
\text { reserves }\end{array}$ \\
\hline 1960 & 1950 & 0.0 & 487.5 & 1462.5 & 430.5 & 918.0 \\
1961 & 1950 & 558.5 & 0.0 & 2508.5 & 1051.3 & 1051.3 \\
1962 & 1950 & 0.0 & 502.4 & 1447.6 & 224.7 & 727.1 \\
1963 & 1950 & 0.0 & 489.5 & 1460.6 & 173.9 & 663.4 \\
1964 & 1950 & 515.9 & 0.0 & 2465.9 & 178.2 & 178.2 \\
1965 & 1950 & 1906.7 & 0.0 & 3856.7 & 739.4 & 739.4 \\
1966 & 2440 & 1864.9 & 0.0 & 4304.9 & 1157.7 & 1157.7 \\
1967 & 2440 & 1013.4 & 0.0 & 3453.4 & 1405.0 & 1405.0 \\
1968 & 2440 & 2275.3 & 0.0 & 4715.3 & 948.8 & 948.8 \\
1969 & 2440 & 2241.1 & 0.0 & 4681.1 & 1055.1 & 1055.1 \\
\hline
\end{tabular}

In millions of SDR, source IFS

Table 2: IMF currency holdings as \% of non-gold reserves

\begin{tabular}{|c|c|c|c|}
\hline & $1960-1971$ & 1972-1983 & 1984-1998 \\
\hline Australia & 25 & 34 & 20 \\
\hline Austria & 7 & 6 & 7 \\
\hline Belgium & 33 & 11 & 25 \\
\hline Canada & 26 & 37 & 44 \\
\hline Denmark & 41 & 19 & 9 \\
\hline Finland & 35 & 43 & 12 \\
\hline France & 143 & 17 & 20 \\
\hline Germany & 8 & 2 & 7 \\
\hline Greece & 35 & 31 & 15 \\
\hline Ireland & 11 & 7 & 7 \\
\hline Italy & 12 & 54 & 9 \\
\hline Japan & 19 & 5 & 5 \\
\hline Netherlands & 36 & 9 & 13 \\
\hline Norway & 21 & 8 & 3 \\
\hline Portugal & 12 & 75 & 30 \\
\hline Spain & 38 & 12 & 4 \\
\hline Sweden & 21 & 14 & 11 \\
\hline United Kingdom & 337 & 46 & 24 \\
\hline United States & 211 & 116 & 33 \\
\hline Average & 59 & 26 & 15 \\
\hline
\end{tabular}

Source: IFS 
Table 3: Volatility comparisons: average variances for 19 countries based on annual data

\begin{tabular}{l|rrr}
\hline & 1961-1971 & $1972-1983$ & $1984-1998$ \\
\hline$\$$ numeraire & 4.6 & 10.6 & 5.9 \\
$\operatorname{var}(\Delta \tilde{p})$ & 8.5 & 8.4 & 4.7 \\
$\operatorname{var}(\Delta \tilde{y})$ & 8.1 & 111.7 & 117.6 \\
$\operatorname{var}(\Delta s)$ & 36.8 & 19.9 & 2.5 \\
$\operatorname{var}(\Delta I M F)(/ 100)$ & & & \\
& & & \\
$D M$ & & & \\
$\operatorname{var}(\Delta \tilde{p})$ & 5.2 & 11.5 & 8.0 \\
$\operatorname{var}(\Delta \tilde{y})$ & 6.3 & 5.4 & 6.4 \\
$\operatorname{var}(\Delta s)$ & 11.7 & 56.0 & 59.3 \\
$\operatorname{var}(\Delta I M F)(/ 100)$ & 32.8 & 15.3 & 2.5 \\
\hline $\operatorname{Da} s O r a i r e$ & &
\end{tabular}

Data source: European Commision and IFS

Table 4: Panel regressions: annual data

\begin{tabular}{|c|c|c|c|c|c|c|}
\hline & & & $\operatorname{var}$ & $\overline{\Delta s)}$ & & \\
\hline & vs $\$$ & vs $\$$ & vs $\$$ & vs DM & vs DM & vs DM \\
\hline constant & $\begin{array}{l}69.78 \\
(2.86)\end{array}$ & $\begin{array}{l}85.66 \\
(3.79)\end{array}$ & $\begin{array}{l}71.38 \\
(2.49)\end{array}$ & $\begin{array}{c}6.76 \\
(1.20)\end{array}$ & $\begin{array}{l}13.59 \\
(3.09)\end{array}$ & $\begin{array}{l}9.53 \\
(2.31)\end{array}$ \\
\hline $\operatorname{var}(\Delta \tilde{p})$ & $\begin{array}{l}3.13^{*} \\
(1.79)\end{array}$ & $\begin{array}{c}2.79 \\
(1.44)\end{array}$ & $\begin{array}{c}4.47^{*} \\
(1.87)\end{array}$ & $\begin{array}{l}2.03^{* *} \\
(9.40)\end{array}$ & $\begin{array}{l}1.85^{* *} \\
(14.08)\end{array}$ & $\begin{array}{l}3.06^{* *} \\
(7.31)\end{array}$ \\
\hline $\operatorname{var}(\Delta \tilde{y})$ & $\begin{array}{l}-3.53^{* *} \\
(3.26)\end{array}$ & $\begin{array}{l}-3.87^{* *} \\
(2.69)\end{array}$ & $\begin{array}{l}-1.43^{* *} \\
(2.42)\end{array}$ & $\begin{array}{l}1.54^{* *} \\
(3.28)\end{array}$ & $\begin{array}{l}1.35^{* *} \\
(5.97)\end{array}$ & $\begin{array}{l}0.58^{*} \\
(1.67)\end{array}$ \\
\hline $\operatorname{var}(\triangle I M F)$ & & $\begin{array}{l}-0.004^{* *} \\
(3.85)\end{array}$ & $\begin{array}{c}-0.005^{* *} \\
(4.30)\end{array}$ & & $\begin{array}{c}-0.002^{* *} \\
(4.73)\end{array}$ & $\begin{array}{l}-0.0012 \\
(1.25)\end{array}$ \\
\hline $\operatorname{covar}(\Delta \tilde{p}, \Delta \tilde{y})$ & & & $\begin{array}{l}7.01^{* *} \\
(2.85)\end{array}$ & & & $\begin{array}{l}2.85^{* *} \\
(4.22)\end{array}$ \\
\hline $\operatorname{covar}(\Delta \tilde{p}, \Delta I M F)$ & & & $\begin{array}{l}-0.42^{* *} \\
(12.24)\end{array}$ & & & $\begin{array}{l}-0.036 \\
(0.24)\end{array}$ \\
\hline $\operatorname{covar}(\Delta \tilde{y}, \Delta I M F)$ & & & $\begin{array}{c}-0.08 \\
(0.45)\end{array}$ & & & $\begin{array}{c}-0.031 \\
(0.35)\end{array}$ \\
\hline $\begin{array}{l}\text { \# observations } \\
\text { weighted adj. } R^{2}\end{array}$ & $\begin{array}{c}57 \\
0.24\end{array}$ & $\begin{array}{c}57 \\
0.24\end{array}$ & $\begin{array}{c}57 \\
0.27\end{array}$ & $\begin{array}{c}57 \\
0.56\end{array}$ & $\begin{array}{c}57 \\
0.65\end{array}$ & $\begin{array}{c}57 \\
0.61\end{array}$ \\
\hline $\begin{array}{l}\text { GLS estimation wit } \\
\text { using white cross- } \\
\text { variances and cova } \\
\text { (1961-1971; } 1972-1 \\
10 \% \text { and } 5 \% \text { levels. }\end{array}$ & $\begin{array}{l}\text { ross-s } \\
\text { tion } \\
\text { nces } \\
198\end{array}$ & $\begin{array}{l}\text { on we } \\
\text { dard } \\
\text { ulated } \\
\text { 998); }\end{array}$ & ${ }_{* *}$ in & pare & ses ar & $\begin{array}{l}\text { Iculate } \\
\text { ountrie } \\
\text { bperio }\end{array}$ \\
\hline
\end{tabular}


Table 5: Panel regressions: monthly data, full sample

\begin{tabular}{l|cccccc}
\hline & vs \$ & vs \$ & vs \$ & vs DM & vs DM & vs DM \\
\hline \multirow{4}{*}{ constant } & & & & & & \\
& 0.0004 & 0.0004 & 0.0004 & 0.0005 & 0.0005 & 0.0005 \\
$\operatorname{var}(\Delta \tilde{m})$ & $(7.64)$ & $(7.83)$ & $(7.61)$ & $(7.98)$ & $(8.30)$ & $(7.94)$ \\
& $8.27^{* *}$ & $8.21^{* *}$ & $8.36^{* *}$ & $21.90^{* *}$ & $21.69^{* *}$ & $21.02^{* *}$ \\
$\operatorname{var}(\Delta \tilde{y})$ & $(2.41)$ & $(2.38)$ & $(2.50)$ & $(3.81)$ & $(3.67)$ & $(3.75)$ \\
& -0.005 & -0.003 & 0.002 & 0.013 & 0.016 & 0.022 \\
$\operatorname{var}(\Delta I M F)$ & $(0.78)$ & $(0.40)$ & $(0.29)$ & $(0.68)$ & $(0.95)$ & $(1.21)^{* *}$ \\
& & -0.0007 & -0.0007 & & $-0.002^{* *}$ & $-0.001^{* *}$ \\
$\operatorname{covar}(\Delta \tilde{m}, \Delta \tilde{y})$ & & $(0.83)$ & $(1.03)$ & & $(3.37)$ & $(2.00)$ \\
& & & -0.078 & & & 0.886 \\
$\operatorname{covar}(\Delta \tilde{m}, \Delta I M F)$ & & & $(0.07)$ & & & $(0.62)$ \\
& & & $-0.976^{* *}$ & & & $-1.653^{* *}$ \\
$\operatorname{covar}(\Delta \tilde{y}, \Delta I M F)$ & & & $(2.45)$ & & & $(4.15)$ \\
& & & -0.02 & & & -0.016 \\
& & & $(1.58)$ & & & $(0.76)$ \\
\# observations & 680 & 680 & 680 & 672 & 672 & 672 \\
weighted adj. $\mathrm{R}^{2}$ & -0.013 & -0.018 & -0.010 & 0.09 & 0.11 & 0.12 \\
\hline G & & & & & & \\
\hline
\end{tabular}

GLS estimation with cross-section weights, t-stats in parentheses are calculated using white cross-section standard errors. Unbalanced panel of 20 countries; annual variances and covariances calculated using monthly data from 1960.01 to $1998.12 ;{ }^{*}$ and ${ }^{* *}$ indicate significance at respectively $10 \%$ and $5 \%$ levels. 
Table 6: Panel regressions: monthly data, small sample

\begin{tabular}{|c|c|c|c|c|c|c|}
\hline & vs $\$$ & vs $\$$ & vs $\$$ & vs DM & vs DM & vs DM \\
\hline constant & $\begin{array}{l}0.0004 \\
(5.44)\end{array}$ & $\begin{array}{l}0.0004 \\
(5.62)\end{array}$ & $\begin{array}{l}0.0003 \\
(5.83)\end{array}$ & $\begin{array}{l}0.0004 \\
(5.50)\end{array}$ & $\begin{array}{c}0.0004 \\
(5.75)\end{array}$ & $\begin{array}{c}0.0004 \\
(4.86)\end{array}$ \\
\hline $\operatorname{var}(\Delta \tilde{m})$ & $\begin{array}{l}2.45 \\
(0.49)\end{array}$ & $\begin{array}{c}3.71 \\
(0.73)\end{array}$ & $\begin{array}{l}4.33 \\
(0.94)\end{array}$ & $\begin{array}{l}17.75^{* *} \\
(2.05)\end{array}$ & $\begin{array}{l}18.64^{* * *} \\
(2.09)\end{array}$ & $\begin{array}{l}20.56^{* *} \\
(2.39)\end{array}$ \\
\hline $\operatorname{var}(\Delta \tilde{y})$ & $\begin{array}{l}-0.010 \\
(0.85)\end{array}$ & $\begin{array}{l}-0.007 \\
(0.47)\end{array}$ & $\begin{array}{l}0.136^{*} \\
(1.83)\end{array}$ & $\begin{array}{c}-0.029^{* *} \\
(3.22)\end{array}$ & $\begin{array}{l}-0.012 \\
(0.96)\end{array}$ & $\begin{array}{l}0.023 \\
(0.34)\end{array}$ \\
\hline $\operatorname{var}(\Delta i l)$ & $\begin{array}{l}2.12 \\
(0.80)\end{array}$ & $\begin{array}{l}2.50 \\
(0.95)\end{array}$ & $\begin{array}{l}2.40 \\
(0.95)\end{array}$ & $\begin{array}{l}8.79^{* *} \\
(3.28)\end{array}$ & $\begin{array}{l}8.37^{* *} \\
(3.31)\end{array}$ & $\begin{array}{l}7.11^{* * *} \\
(3.30)\end{array}$ \\
\hline $\operatorname{var}(\triangle I M F)$ & & $\begin{array}{l}-0.000 \\
(0.93)\end{array}$ & $\begin{array}{l}-0.000 \\
(0.00)\end{array}$ & & $\begin{array}{l}-0.003^{* *} \\
(2.75)\end{array}$ & $\begin{array}{c}-0.003^{* *} \\
(3.47)\end{array}$ \\
\hline $\operatorname{covar}(\Delta \tilde{m}, \Delta \tilde{y})$ & & & $\begin{array}{l}14.02^{* *} \\
(2.59)\end{array}$ & & & $\begin{array}{l}-0.358 \\
(0.08)\end{array}$ \\
\hline $\operatorname{covar}(\Delta \tilde{m}, \Delta i l)$ & & & $\begin{array}{l}-21.29 \\
(1.43)\end{array}$ & & & $\begin{array}{l}35.88^{*} \\
(1.84)\end{array}$ \\
\hline $\operatorname{covar}(\Delta \tilde{m}, \Delta I M F)$ & & & $\begin{array}{l}-0.486 \\
(0.87)\end{array}$ & & & $\begin{array}{l}-1.60^{*} \\
(1.70)\end{array}$ \\
\hline $\operatorname{covar}(\Delta \tilde{y}, \Delta i l)$ & & & $\begin{array}{r}-1.877 \\
(1.06)\end{array}$ & & & $\begin{array}{l}4.49^{* *} \\
(2.03)\end{array}$ \\
\hline $\operatorname{covar}(\Delta \tilde{y}, \Delta I M F)$ & & & $\begin{array}{l}-0.086 \\
(1.36)\end{array}$ & & & $\begin{array}{l}-0.001 \\
(0.02)\end{array}$ \\
\hline $\operatorname{covar}(\Delta i l, \Delta I M F)$ & & & $\begin{array}{l}-0.902 \\
(1.18)\end{array}$ & & & $\begin{array}{l}-0.654 \\
(1.02)\end{array}$ \\
\hline $\begin{array}{l}\text { \# observations } \\
\text { weighted adj. } \mathrm{R}^{2}\end{array}$ & $\begin{array}{c}216 \\
-0.13\end{array}$ & $\begin{array}{c}216 \\
-0.13\end{array}$ & $\begin{array}{c}216 \\
-0.10\end{array}$ & $\begin{array}{l}216 \\
0.06\end{array}$ & $\begin{array}{l}216 \\
0.07\end{array}$ & $\begin{array}{l}216 \\
0.12\end{array}$ \\
\hline
\end{tabular}

GLS estimation with cross-section weights, t-stats in parentheses are calculated using white cross-section standard errors. Balanced panel of 6 countries (Canada, France, Italy, UK, Australia and either the US or Germany); annual variances and covariances calculated using monthly data from 1963.01 to $1998.12 ;{ }^{*}$ and ${ }^{* *}$ indicate significance at respectively $10 \%$ and $5 \%$ levels. 
Table 7: The interbellum

\begin{tabular}{|c|c|c|c|c|c|}
\hline & \multirow[t]{2}{*}{ period } & \multicolumn{2}{|c|}{ standard deviation } & \multicolumn{2}{|c|}{ mean } \\
\hline & & $\Delta s$ & $\Delta \tilde{m}$ & $\Delta s$ & $\Delta \tilde{m}$ \\
\hline Austria & 21:05-22:12 & 23.85 & 12.87 & 26.09 & 23.11 \\
\hline Belgium & 20:07-26:11 & 8.08 & 2.08 & 1.00 & 1.27 \\
\hline Denmark & 20:08-26:05 & 4.65 & 1.88 & -0.67 & 0.30 \\
\hline Finland & 20:08-24:01 & 11.14 & 2.54 & 1.16 & 0.90 \\
\hline France & 19:08-26:11 & 7.19 & 1.80 & 1.64 & 0.89 \\
\hline Germany & 19:08-24:10 & 105.14 & 97.07 & 41.15 & 38.69 \\
\hline Italy & 20:03-28:11 & 5.50 & 1.64 & 0.11 & 0.39 \\
\hline Japan & 20:08-28:11 & 2.63 & 6.48 & 0.09 & 0.52 \\
\hline Netherlands & 19:08-25:04 & 2.19 & 1.77 & -0.07 & 0.30 \\
\hline Norway & 20:08-26:10 & 5.15 & 2.24 & -0.52 & 0.20 \\
\hline Spain & 20:08-28:11 & 2.34 & 1.54 & -0.05 & 0.57 \\
\hline Sweden & 19:08-25:04 & 2.66 & 2.64 & -0.11 & 0.03 \\
\hline Switzerland & 20:08-24:10 & 2.18 & 2.46 & -0.17 & 0.68 \\
\hline United Kingdom & 19:08-25:04 & 2.58 & 1.60 & -0.11 & 0.38 \\
\hline$r$ with $\sigma(\Delta s)$ & & & 0.49 & & 0.59 \\
\hline$t_{r}$ & & & 1.95 & & 2.54 \\
\hline$r$ with $\mu(\Delta s)$ & & & & & 0.82 \\
\hline$t_{r}$ & & & & & 5.04 \\
\hline
\end{tabular}


Table 8: Post-Bretton Woods

\begin{tabular}{l|cccc}
\hline \multicolumn{1}{c|}{ 1974.01-1998.12 } & \multicolumn{2}{c}{ versus US } & \multicolumn{2}{c}{ versus Germany } \\
& $\Delta s$ & $\Delta(\tilde{m}-\tilde{y})$ & $\Delta s$ & $\Delta(\tilde{m}-\tilde{y})$ \\
\hline Australia & 2.3 & 1.1 & 3.9 & 1.9 \\
Austria & 2.7 & 2.6 & 2.7 & 3.1 \\
Belgium & 3.4 & 3.9 & 1.3 & 3.8 \\
Canada & 1.1 & 1.4 & 3.5 & 2.3 \\
Denmark & 2.6 & 3.0 & 2.8 & 3.1 \\
Finland & 2.5 & 2.5 & 3.1 & 3.0 \\
France & 3.2 & 1.6 & 1.3 & 2.0 \\
Germany & 3.3 & 1.9 & 0.0 & 0.0 \\
Greece & 2.4 & 3.6 & 3.1 & 4.1 \\
Ireland & 2.6 & 3.6 & 3.0 & 3.9 \\
Italy & 3.2 & 2.4 & 2.2 & 2.9 \\
Japan & 3.5 & 1.7 & 3.2 & 2.4 \\
Korea (South) & 2.9 & 3.2 & 4.3 & 3.7 \\
Netherlands & 3.3 & 2.9 & 0.5 & 3.3 \\
Norway & 2.3 & 4.7 & 2.8 & 4.8 \\
Portugal & 2.7 & 5.1 & 3.2 & 5.1 \\
South-Africa & 3.2 & 3.2 & 4.2 & 3.6 \\
Spain & 2.6 & 2.4 & 3.2 & 2.8 \\
Sweden & 2.5 & 2.4 & 3.2 & 2.8 \\
Switzerland & 3.1 & 2.8 & 3.0 & 3.2 \\
United Kingdom & 3.2 & 1.6 & 2.7 & 2.2 \\
United States & 0.0 & 0.0 & 3.3 & 1.9 \\
& & & & \\
Average & 2.8 & 2.7 & 2.9 & 3.1 \\
Standard deviation & 0.6 & 1.1 & 0.9 & 0.9 \\
\hline Note: standard devation & 0.9 & &
\end{tabular}

Note: standard deviations of log differences x 100. 
Table 9: Some ERM Experiences

\begin{tabular}{|c|c|c|c|c|}
\hline & & 79.01-83.03 & $83.04-92.08$ & $92.09-98.12$ \\
\hline \multicolumn{5}{|l|}{ France } \\
\hline \multirow[t]{2}{*}{$\Delta s$ excl. realignments } & $\mu$ & 0.20 & 0.08 & -0.02 \\
\hline & $\sigma$ & 0.67 & 0.47 & 0.63 \\
\hline \multirow[t]{2}{*}{$\Delta s$} & $\mu$ & 0.53 & 0.11 & -0.02 \\
\hline & $\sigma$ & 1.43 & 0.56 & 0.63 \\
\hline \multirow[t]{2}{*}{$\Delta(\tilde{m}-\tilde{y})$} & $\mu$ & 0.47 & -0.09 & -0.47 \\
\hline & $\sigma$ & 1.87 & 2.05 & 1.80 \\
\hline \multirow[t]{2}{*}{$\Delta\left(i_{\text {off }}-i_{\text {on }}\right)$} & $\mu$ & -0.01 & 0.00 & 0.00 \\
\hline & $\sigma$ & 0.31 & 0.08 & 0.05 \\
\hline \multicolumn{5}{|l|}{ Italy } \\
\hline \multirow[t]{2}{*}{$\Delta s$ excl. realignments } & $\mu$ & 0.23 & 0.14 & 0.34 \\
\hline & $\sigma$ & 0.95 & 0.68 & 2.72 \\
\hline \multirow[t]{2}{*}{$\Delta s$} & $\mu$ & 0.53 & 0.22 & 0.34 \\
\hline & $\sigma$ & 1.35 & 0.86 & 2.46 \\
\hline \multirow[t]{2}{*}{$\Delta(\tilde{m}-\tilde{y})$} & $\mu$ & 0.89 & 0.21 & -0.32 \\
\hline & $\sigma$ & 3.04 & 3.18 & 2.46 \\
\hline \multirow[t]{2}{*}{$\Delta\left(i_{\text {off }}-i_{\text {on }}\right)$} & $\mu$ & -0.01 & 0.00 & 0.00 \\
\hline & $\sigma$ & 0.30 & 0.08 & 0.03 \\
\hline \multicolumn{5}{|l|}{ Netherlands } \\
\hline \multirow[t]{2}{*}{$\Delta s$ excl. realignments } & $\mu$ & 0.02 & 0.00 & 0.00 \\
\hline & $\sigma$ & 0.67 & 0.21 & 0.13 \\
\hline \multirow[t]{2}{*}{$\Delta s$} & $\mu$ & 0.07 & 0.00 & 0.00 \\
\hline & $\sigma$ & 0.72 & 0.21 & 0.13 \\
\hline \multirow[t]{2}{*}{$\Delta(\tilde{m}-\tilde{y})$} & $\mu$ & 0.08 & -0.08 & -0.16 \\
\hline & $\sigma$ & 2.81 & 4.15 & 3.05 \\
\hline \multirow[t]{2}{*}{$\Delta\left(i_{\text {off }}-i_{\text {on }}\right)$} & $\mu$ & 0.00 & 0.00 & 0.00 \\
\hline & $\sigma$ & 0.10 & 0.03 & 0.02 \\
\hline
\end{tabular}

Note: all variables except $\Delta\left(i_{\text {off }}-i_{\text {on }}\right)$ are vis á vis Germany. 
Table 10: EMU countries and German provinces

\begin{tabular}{|c|c|c|c|c|}
\hline \multirow[t]{2}{*}{ annual data 1990-1998 } & \multicolumn{4}{|c|}{ standard deviation of } \\
\hline & $\Delta s$ & $\Delta \tilde{p}$ & $\Delta \tilde{m}$ & $\Delta \tilde{y}$ \\
\hline Austria & 1.11 & 0.72 & 3.50 & 1.37 \\
\hline Belgium & 1.04 & 0.59 & 4.67 & 1.64 \\
\hline Finland & 7.68 & 1.77 & 3.84 & 5.36 \\
\hline France & 0.85 & 0.74 & 5.54 & 1.80 \\
\hline Greece & 5.78 & 3.98 & 3.31 & 2.36 \\
\hline Ireland & 5.58 & 2.02 & 5.23 & 3.56 \\
\hline Italy & 8.01 & 1.61 & 3.87 & 1.79 \\
\hline Netherlands & 0.29 & 1.08 & 2.86 & 1.86 \\
\hline Portugal & 4.24 & 2.51 & 5.52 & 1.52 \\
\hline Spain & 5.75 & 1.05 & 3.88 & 1.64 \\
\hline Baden-Württemberg & 0.00 & 0.43 & 2.33 & 1.14 \\
\hline Bayern & 0.00 & 0.37 & 1.81 & 0.79 \\
\hline Bremen & 0.00 & 0.39 & 2.88 & 1.58 \\
\hline Hamburg & 0.00 & 0.61 & 1.90 & 0.94 \\
\hline Hessen & 0.00 & 0.40 & 3.50 & 0.81 \\
\hline Niedersachsen & 0.00 & 0.34 & 2.92 & 1.07 \\
\hline Rheinland-Pfalz & 0.00 & 0.41 & 2.58 & 0.62 \\
\hline Saarland & 0.00 & 0.37 & 2.91 & 1.40 \\
\hline Schleswig-Holstein & 0.00 & 0.46 & 3.94 & 0.80 \\
\hline$r$ with $\Delta s$ & & 0.74 & 0.45 & 0.71 \\
\hline$t_{r}$ & & 4.57 & 2.08 & 4.18 \\
\hline
\end{tabular}


Table A1: Data availability, monthly dataset

\begin{tabular}{|c|c|c|c|c|c|}
\hline & $M$ & & $Y$ & $P$ & il \\
\hline Australia & 60:1-98:12 & M1 & 60:1-98:12 & $60: 2-98: 12^{3}$ & 60:1-98:12 \\
\hline Austria & 60:1-98:10 & M1 & 60:1-98:12 & 60:1-98:12 & 71:1-98:12 \\
\hline Belgium & 64:1-98:12 & $\mathrm{M} 1^{1}$ & $60: 1-98: 12$ & $60: 1-98: 12$ & 63:9-98:12 \\
\hline Canada & 60:1-98:12 & M1 & 60:1-98:12 & 60:1-98:12 & 60:1-98:12 \\
\hline Denmark & 60:1-98:12 & M1 & 74:1-98:12 & $67: 1-98: 12$ & 60:1-98:12 \\
\hline Finland & 69:1-98:12 & Currency & 60:1-98:12 & 60:1-98:12 & $92: 11-98: 12$ \\
\hline France & 60:1-98:12 & M1 & 60:1-98:12 & 60:1-98:12 & 60:1-98:12 \\
\hline Germany & 61:1-98:12 & M1 & $60: 1-98: 12$ & 60:1-98:12 & 60:1-98:12 \\
\hline Greece & 68:12-98:12 & Currency & 60:1-98:12 & 60:1-98:12 & $\begin{array}{l}86: 5-88: 12 \\
97: 5-98: 12\end{array}$ \\
\hline Ireland & 67:1-98:12 & Currency & 60:1-98:12 & $60: 2-98: 12^{3}$ & 64:1-98:12 \\
\hline Italy & 62:1-98:12 & M1 & 60:1-98:12 & 60:1-98:12 & 60:1-98:12 \\
\hline Japan & 63:1-98:12 & M1 & 60:1-98:12 & 60:1-98:12 & 66:11-98:12 \\
\hline Korea & 60:1-98:12 & M1 & 60:1-98:12 & 70:1-98:12 & 73:5-98:12 \\
\hline Netherlands & 60:1-97:12 & M1 & 60:1-98:12 & 60:1-98:12 & 64:11-98:12 \\
\hline Norway & 60:1-98:12 & Broad M & 60:1-98:12 & 60:1-98:12 & $\begin{array}{c}\text { 61:9-80:7 } \\
80: 10-98: 12\end{array}$ \\
\hline Portugal & 76:1-98:12 & Currency & 60:1-98:12 & 60:1-98:12 & $\begin{array}{c}60: 1-64: 4 \\
76: 1-98: 12\end{array}$ \\
\hline South-Africa & $\begin{array}{c}60: 1-91: 6 \\
92: 1-98: 12\end{array}$ & M1 & 61:1-98:12 & 60:1-98:12 & 60:1-98:12 \\
\hline Spain & 62:1-98:12 & M1 & 61:1-98:12 & 60:1-98:12 & 78:3-98:12 \\
\hline Swede & 61:1-98:12 & Broad M & 60:1-98:12 & 60:1-98:12 & $60: 1-95: 12$ \\
\hline Switzerland & 60:1-98:12 & M1 & 63:2-98:12 & 60:1-98:12 & 64:1-98:12 \\
\hline $\begin{array}{l}\text { UK } \\
\text { US }\end{array}$ & $\begin{array}{l}60: 1-98: 12 \\
60: 1-98: 12\end{array}$ & $\begin{array}{l}\mathrm{M}^{2} \\
\mathrm{M} 1\end{array}$ & $\begin{array}{l}60: 1-98: 12 \\
60: 1-98: 12\end{array}$ & $\begin{array}{l}60: 1-98: 12 \\
60: 1-98: 12\end{array}$ & $\begin{array}{l}60: 1-98: 12 \\
60: 1-98: 12\end{array}$ \\
\hline
\end{tabular}

${ }^{1}$ Currency (line 34a) until 79:12, thereafter M1. Ratio-spliced. ${ }^{2}$ Broad money (line 35L) until 75:5, thereafter M0. Ratio-spliced. ${ }^{3}$ Interpolated from quarterly data. 


\section{Figures}

Figure 1: The cross (1960-1998)
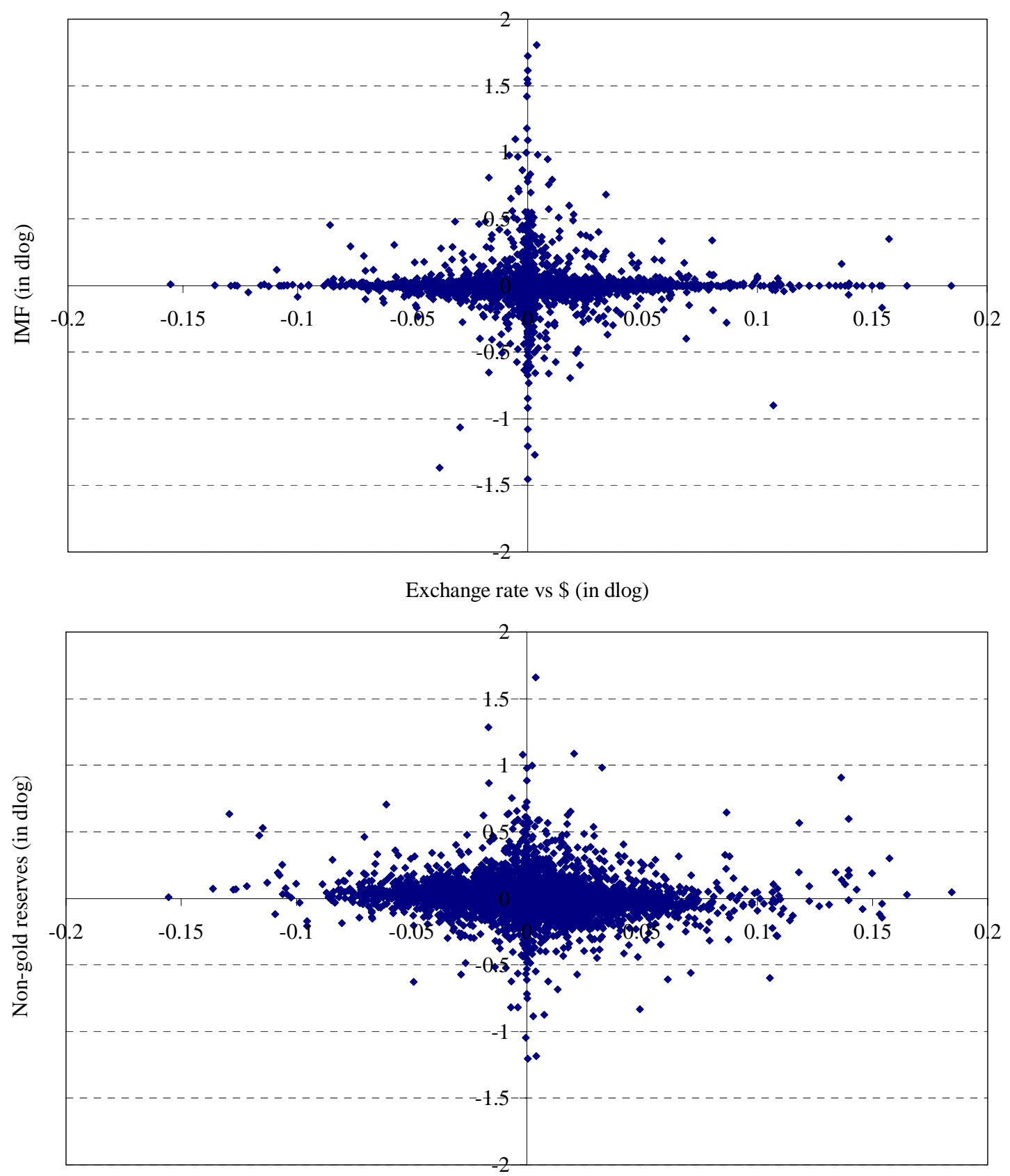

Exchange rate vs \$ (in dlog) 
Figure 2: The case of the United Kingdom (all variables in absolute changes)
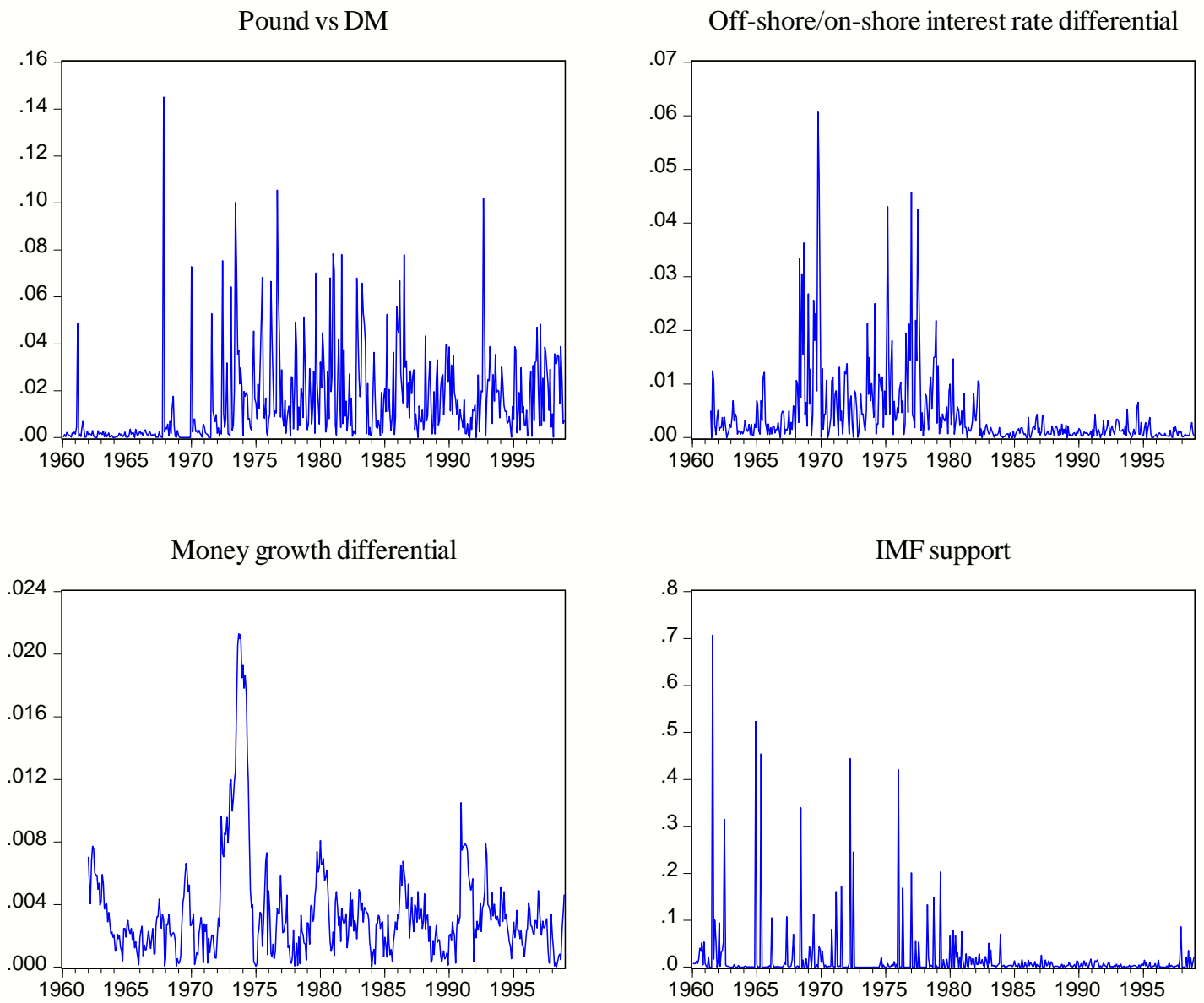
Figure 3: Percentage growth in demand deposits in nine regions of the US monetary union (annual data 1929-1983)

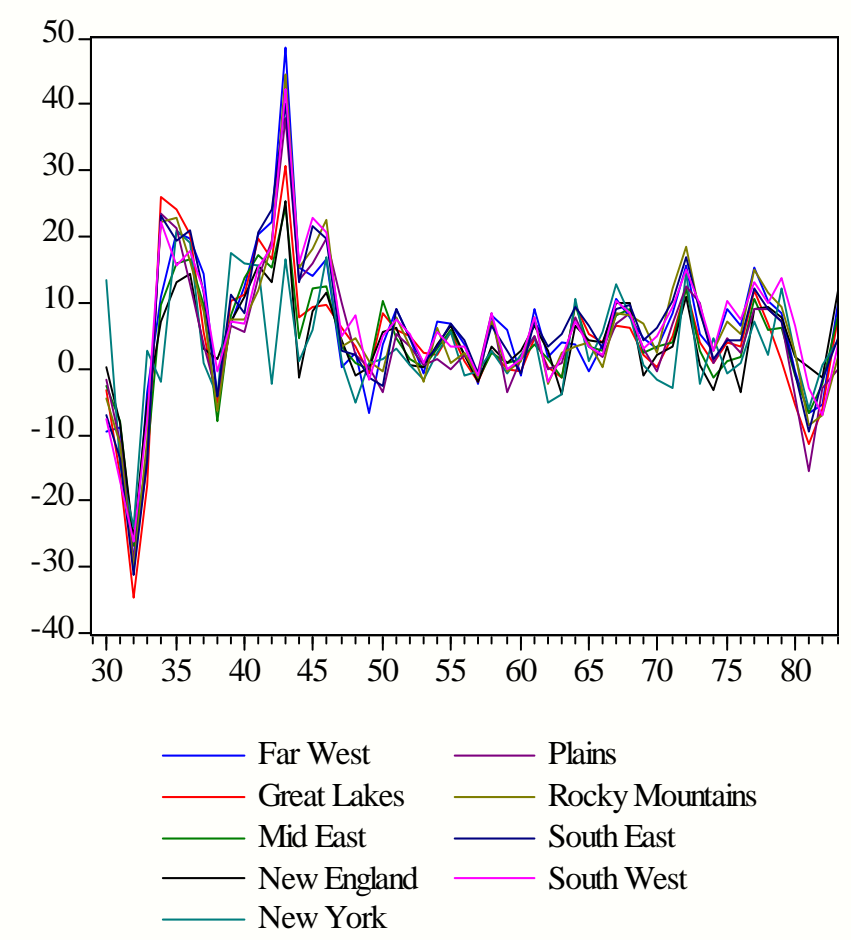

Figure 4: Percentage growth in income in nine regions of the US monetary union (annual data 1929-1983)

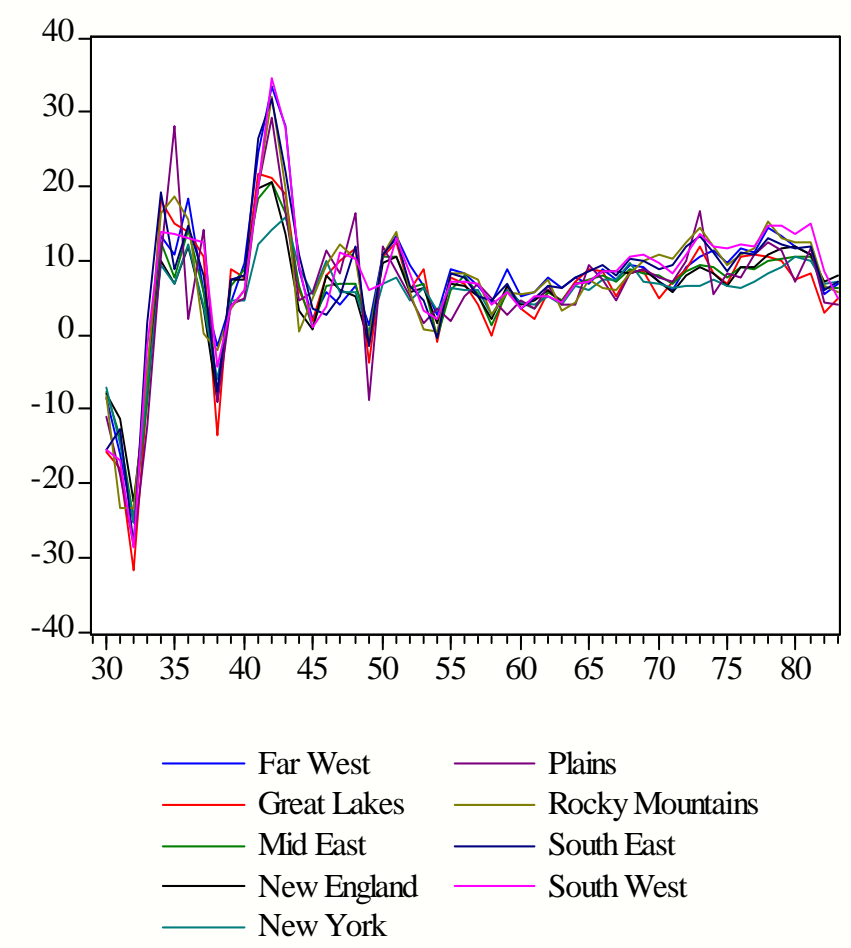

